\title{
Cumulus Cells Are Potential Candidates for Cell Therapy
}

\author{
ESLAM ESSAM MOHAMMED ${ }^{1}$, SEMA YILMAZ ${ }^{2}$, OYA ALAGOZ AKCIN ${ }^{3}$, BARBAROS NALBANTOGLU ${ }^{1}$, \\ CEM FICICIOGLU $^{3}$, FIKRETTIN SAHIN ${ }^{4}$ and ESRA AYDEMIR COBAN ${ }^{4}$ \\ ${ }^{1}$ Department of Biochemistry, Yildiz Technical University, Istanbul, Turkey; \\ ${ }^{2}$ Division of Pediatric Hematology/Oncology, Health Science University Kartal Lutfi \\ Kirdar Education and Research Hospital, Istanbul, Turkey; \\ ${ }^{3}$ Department of Gynecology and Obstetrics, Yeditepe University Faculty of Medicine, Istanbul, Turkey; \\ ${ }^{4}$ Department of Bioengineering and Genetics, Yeditepe University Faculty of Medicine, Istanbul, Turkey
}

\begin{abstract}
Background/Aim: Cumulus cells (CCs) originate from the membrane granulosa cells and surround oocytes during follicle maturation. CCs produce high levels of hyaluronan that targets $C D 44$, which is a major tumorigenic marker. This study aimed to investigate whether CCs have a role in cell therapy by targeting CD44 in pancreatic cancer cells. Materials and Methods: CCs were isolated from the oocytes and incubated in a hypoxic environment. BxPC-3 pancreatic cancer cells were treated with $C C$ conditioned media for three days. Results: Conditioned media of CC cells incubated in hypoxic conditions caused a $25 \%$ reduction in the viability of BXPC-3 cells. Expression of anti-apoptotic genes was down-regulated, while that of pro-apoptotic genes was upregulated. An increased number of BxPC-3 cells exhibited increased levels of reactive oxygen species and arrested in the synthesis (S) phase of the cell cycle. Conclusion: CCs conditioned medium induced apoptosis of pancreatic cancer cells.
\end{abstract}

Cumulus cells (CCs) are a specialized group of granulosa cells, which are in intimate contact with oocytes $(1,2)$ both in the ovarian follicle and after ovulation. CCs are removed in routine human intra-cytoplasmic sperm injection (ICSI) practices for better capturing of the polar body. CCs play an essential role in regulating oocyte maturation $(3,4)$; they surround the mature oocyte and give rise to a cumulus mass

This article is freely accessible online.

Correspondence to: Esra Aydemir Coban, Molecular Biologist, $\mathrm{PhD}$, Department of Genetics and Bioengineering, Yeditepe University, İnönü Mah. Kayışdağı Cad. 326A 26 Ağustos Yerleşimi 34755 Ataşehir - İstanbul, Istanbul, Turkey. Tel: +90 2165780000 , 3192, e-mail: esra.aydemir@yeditepe.edu.tr

Key Words: BxPC-3, granulosa cells, oocyte, pancreatic cancer. of several millimeters (5). Several studies on CCs have focused on their role in oocyte maturation and fertilization and on their use as novel non-invasive diagnostic biomarkers to determine oocyte quality (6).

Many types of cancers are characterized by elevated levels of reactive oxygen species (ROS), which play an essential role in cell proliferation, differentiation, and cell survival (7). CCs have a protective effect against ROS, but only to a certain extent. The process of $\mathrm{CC}$ expansion requires the production of hyaluronic acid $(8,9)$, which is the primary CD44 binding molecule overexpressed in many solid tumors, such as pancreatic cancer (10). CD44 is a non-kinase transmembrane glycoprotein, which has been shown to be overexpressed in a variety of cells such as cancer stem cells and mutations in this gene are thought to play a role in tumorigenesis (11). Targeting this protein through CCs might have an anti-carcinogenic effect on pancreatic cancer cells.

\section{Materials and Methods}

Tissue collection and sample preparation. The tissue of origin of CCs was obtained from the IVF lab. Tissues were minced in phosphate buffered saline (PBS) by pipetting vigorously and transferred into T25 flasks coated with Type I Collagen (STEMCELL Technologies, Kent, WA, USA). CCs were cultured in RPMI-1640 (Life Technologies, Grand Island, NY, USA), supplemented with 10\% FBS (Life Technologies) and 1\% penicillin/streptomycin/amphotericin (PSA) Life Technologies), and incubated in hypoxic conditions $\left(2 \% \mathrm{O}_{2}\right)$. Floating tissues and cells flask were discarded and the medium was replaced with fresh medium and left in the incubator for three to four days. Conditioned medium was collected and filtered using a $0.22 \mu \mathrm{m}$ filter and kept in $-80^{\circ} \mathrm{C}$ until used.

Ethical approval. This study is involved human participants and ethical approval was obtained. Informed consent was obtained from all individual participants included in the study.

Characterization of CCs by flow cytometry and gene expression analyses. Cells were dissociated from the flask using $0.25 \%$ 
a

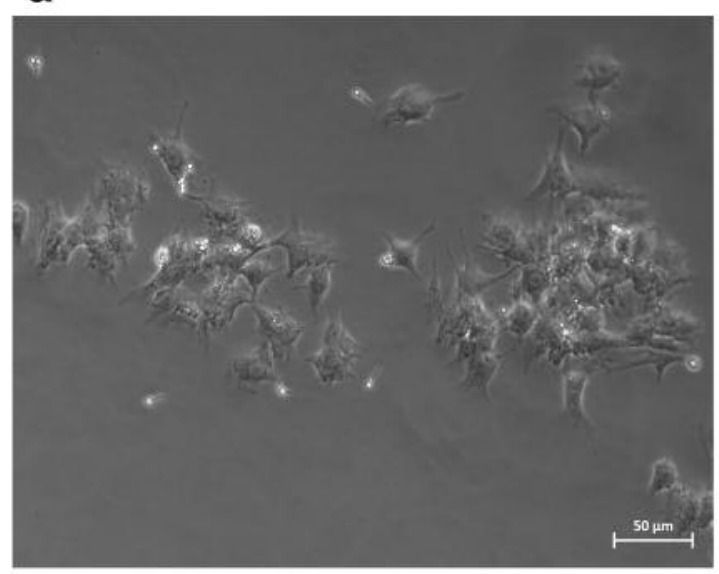

b

S1 $\quad$ S2 S3 S4 S5 S6 S7 S8

$\operatorname{cox} 2$

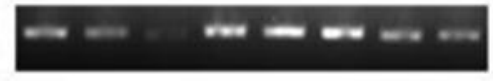

HAS2

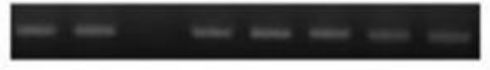

PTX3

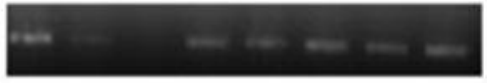

CX43

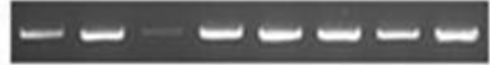

Figure 1. Morphology and gene expression of CCs. a) Cumulus cell under light microscope b) Gene expression analysis of CCs samples show expression of COX2, PTX3, CX43 and HAS2 genes. CCs: Cumulus cells, S: samples.

Trypsin-EDTA (Life Technologies), re-suspended in PBS, and incubated with phycoerythrin-conjugated (PE-conjugated) antiCD44 antibody (MEM-263, Abcam, USA) for further analysis by flow cytometry using BD FACS Calibur (Becton Dickinson, San Jose, CA, USA). Human CCs are characterized by the expression of pentraxin 3 (PTX3) (12), hyaluronic acid synthase 2 (HAS2) (13), Cyclooxygenase 2 (COX2) (14), and Connexin 43 (15). Total RNA was isolated by NucleoSpin ${ }^{\circledR}$ RNA kit (740955.50, MACHEREY-NAGEL ${ }^{\circledR}$, Duren, Germany) according to the manufacturer's protocols. QuantiTect Reverse Transcription Kit (Qiagen ${ }^{\circledR}$, Germantown, MD, USA) was used to synthesize cDNA that was used as a template for conventional PCR using Q5 ${ }^{\circledR}$ Hot Start High-Fidelity 2X Master Mix (NEW ENGLAND BIOLAB ${ }^{\circledR}$, Beverly, MA, USA). The PCR products were analyzed by agarose electrophoresis and the bands were further visualized under UV light.

Indirect co-culture. BxPC-3 cells (CRL-1687, ATCC, USA), a pancreatic adenocarcinoma cell line, were grown in complete medium (RPMI1460 + 10\% heat-inactivated fetal bovine serum + $1 \%$ penicillin-streptomycin/amphotericin). Cells were seeded in two 6 -well plates at a density of $2 \times 10^{5}$ cells per well and incubated under normoxia $\left(18 \% \mathrm{O}_{2}\right)$ with various concentrations of $\mathrm{CCs}$ conditioned medium (previously incubated in hypoxic conditions, collected, and filtered) including 100\%, 80\%, 60\%, and 50\%. Conditioned media from a pancreatic epithelial healthy cell line (hTERT-HPNE) was separately used to assess the specificity of the detrimental effect of CC conditioned media.

Apoptotic assays via annexin $V$, and multi-caspase assays. Early apoptotic cells were confirmed by using the Annexin V Kit (MCH100105, Merck, Darmstadt, Germany) and Multi-Caspase Assay Kit (MCH100108, Merck) according to manufacturer's protocol. Cellular samples were incubated with the Muse ${ }^{\mathrm{TM}}$ Annexin V \& Dead Cell reagent (MCH100102, Merck) containing $1 \%$ FBS and apoptotic/dead cells were analyzed by Muse ${ }^{\circledR}$ Cell Analyzer.
Quantification of apoptotic genes. Quantitative real-time PCR was performed using TaqMan probe qPCR master mix (Promega ${ }^{\circledR}$, USA). Exon spanning primer probes (all purchased from Thermo scientific, USA) targeting Bak (Hs00832876_g1), Bax (Hs99999001_m1), Bcl2 (Hs01048932_g1), Casp3 (Hs00234387_m1), TNF (Hs00174128_m1), TP53 (Hs01034249_m1) and the housekeeping gene GAPDH (Hs02786624_g1) were used. CFX96 ${ }^{\circledR}$ real-time PCR system (BioRad) was used and data analysis was performed using CFX manager software.

Reactive oxygen species (ROS) measurement. Reactive oxygen species (ROS) were quantitated by Muse ${ }^{\circledR}$ Oxidative Stress Kit (MCH100111, Merck) according to the manufacturer's protocol. Briefly, cell samples prepared at a density of $1 \times 10^{6}$ to $1 \times 10^{7}$ cells/ml, were incubated with the Muse ${ }^{\circledR}$ Oxidative Stress working solution, and analyzed by Muse ${ }^{\circledR}$ Cell Analyzer.

Cell cycle analysis. The effect of CC conditioned media on the cell cycle of BXPC-3 cells was determined by Muse ${ }^{\mathrm{TM}}$ Cell Cycle Kit (Merck) according to the manufacturer's protocol. Briefly, ice cold $70 \%$ ethanol was added slowly, for at least $3 \mathrm{~h}$, to cells while mixing and were then mixed with Muse ${ }^{\mathrm{TM}}$ Cell Cycle Reagent. Cells were incubated for $30 \mathrm{~min}$ at room temperature in the dark and analyzed by Muse ${ }^{\circledR}$ Cell Analyzer.

Cell viability assay for combination therapy. BXPC-3 cells were treated with gemcitabine (BioVision, Milpitas, CA, USA) combined with $\mathrm{CC}$ conditioned media and their synergistic effect on cell viability was assessed by the MTS assay using CellTiter 96 ${ }^{\circledR}$ AQueous MTS Reagent Powder (Promega ${ }^{\circledR}$, Mannheim, Germany). The cells were seeded in 96-well plates and incubated with different concentrations of gemcitabine and $\mathrm{CC}$ conditioned media for $72 \mathrm{~h}$. A colorimetric viability assay to assess the mitochondrial activity of cells was performed where the tetrazolium dye MTT 3-(4,5-dimethylthiazol-2-yl)-2,5diphenyltetrazolium bromide is reduced to formazan crystals which were dissolved in DMSO. Optical density was measured 


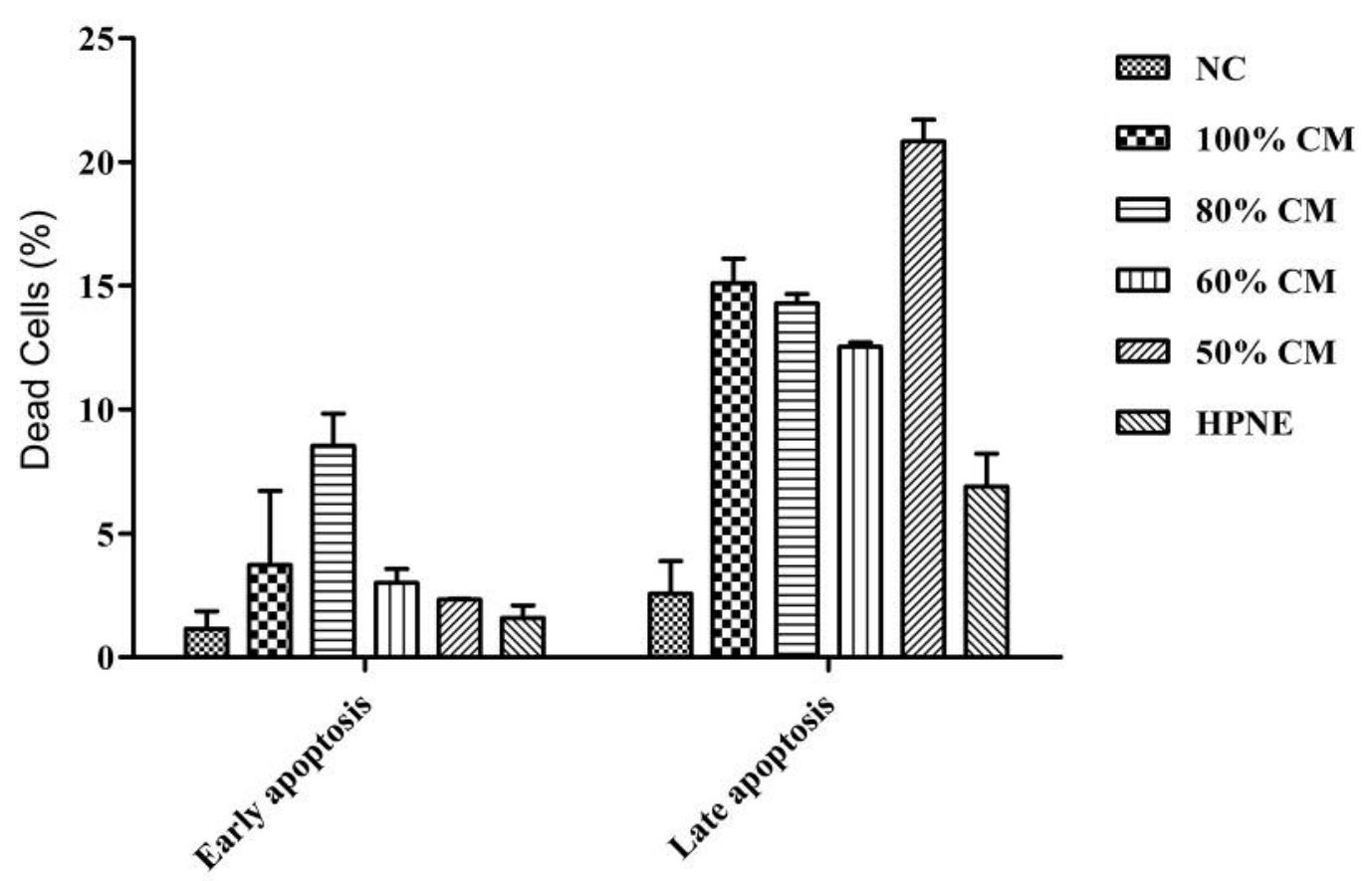

Figure 2. CCs conditioned media induced apoptosis of BxPC-3 cells. Early and late apoptotic BXPC-3 cells treated with various concentrations of CCs or hTERT-HPNEs CM. CM: Conditioned media, hTERT-HPNEs: Immortalized healthy human pancreatic epithelial cells, $p<0.0001$.

at $490 \mathrm{~nm}$ using a microplate reader (Biotek Instruments ELx800 Absorbance Micro-plate Reader).

Direct co-culture. BxPC-3 cells were transfected with GFP plasmid using FuGENE ${ }^{\circledR}$ HD Transfection Reagent (Promega, Mannheim, Germany). GFP-tagged BxPC-3 cells were directly co-cultured with PKH26 Red (Merck) fluorescent labeled Human Cumulus Cells for $72 \mathrm{~h}$. Live images were captured by Olympus Imaging System.

\section{Results}

Isolation and characterization of cumulus cells. CCs were successfully isolated as illustrated in Figure 1a. The majority of cells expressed high levels of CD44 (data not shown). The cells express COX2, PTX3, CX43, and HAS2 (Figure 1b).

Apoptotic assays. Incubation of BxPC-3 cells with various concentrations of $\mathrm{CCs}$ conditioned medium (previously incubated and collected from hypoxia) caused up to $25 \%$ cell death as shown in Figure 2. Treatment of BxPC-3 cells with hTERT-HPNE conditioned medium did not induce apoptosis, suggesting that cell death was specifically due to the effects of the conditioned media of CCs (Figure 2).

Multi-caspase assay. Incubation of $\mathrm{BxPC}-3$ cells with various concentrations of CCs conditioned medium induced an increase in the percentage of caspase activity by $34 \%$ (Figure 3).

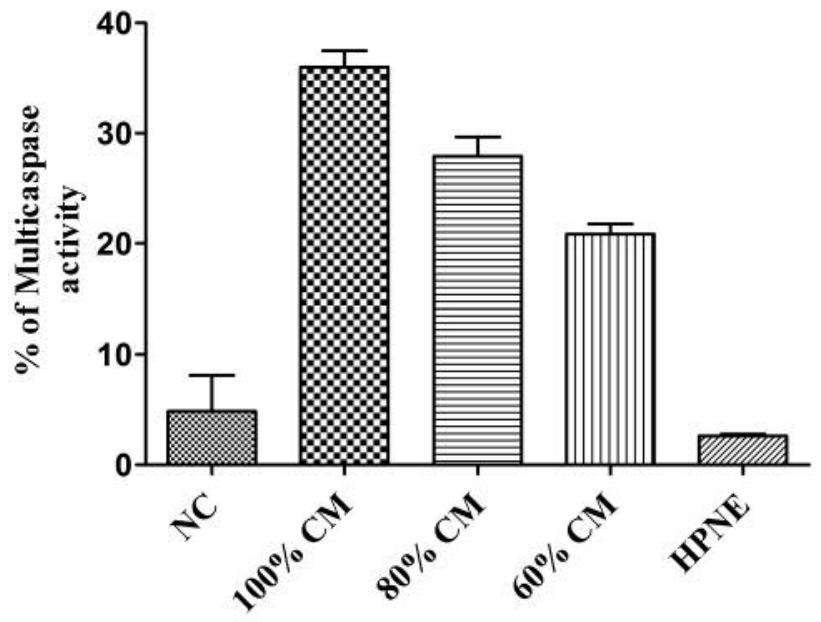

Figure 3. CCs conditioned media increased the activity of caspases. $B x P C-3$ cells treated with various concentrations of CCs $C M, p<0.0001$.

$q R T-P C R$. Upon incubation of BxPC-3 cells with CCs conditioned medium the expression of $B A X$ and BCL2 genes was downregulated and that of $B A K$ and $T N F$ genes was upregulated, while expression of CASP3 and TP53 did not change significantly (Figure 4). 


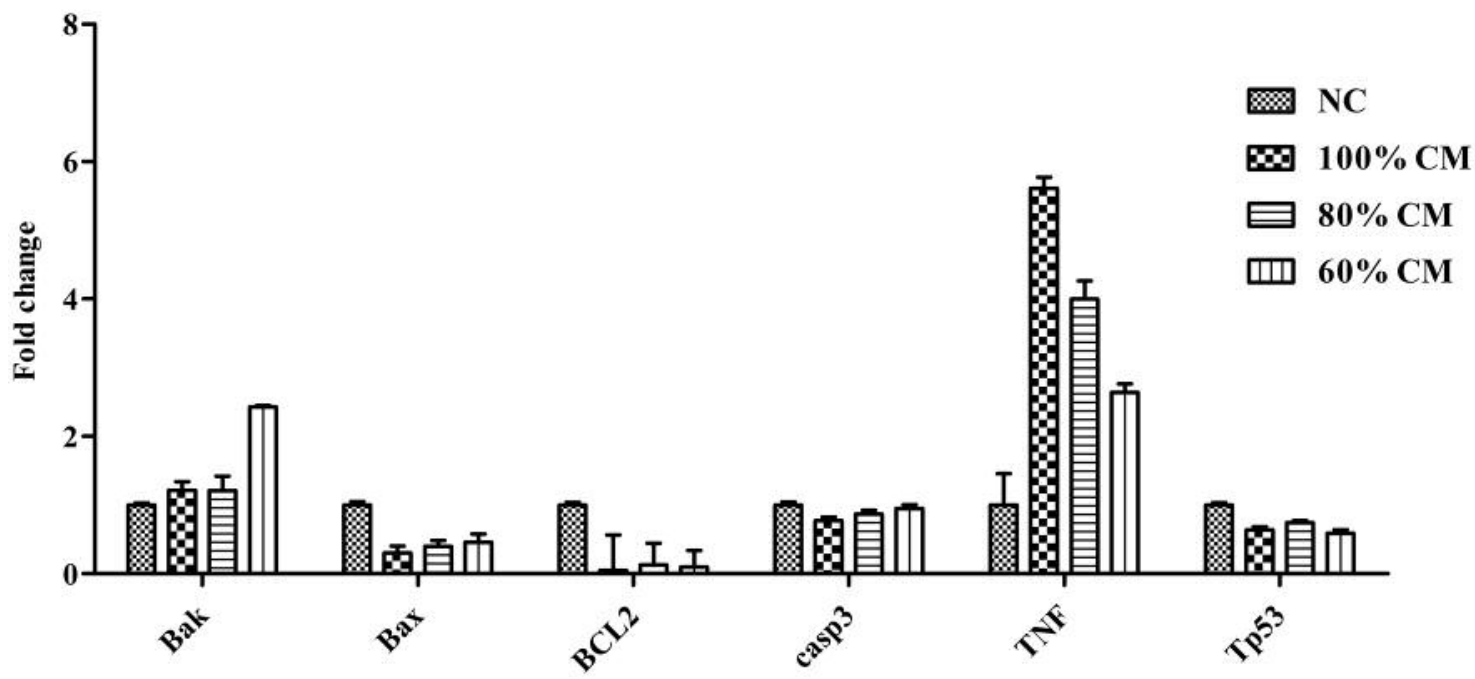

Figure 4. Expression of apoptosis-related genes in BxPC-3 cells tretated with CCs conditioned media. Apoptotic gene expression of BxPC-3 cells treated with various concentrations of CCs CM. NC: Negative control; CM: conditioned medium, $p<0.0001$.

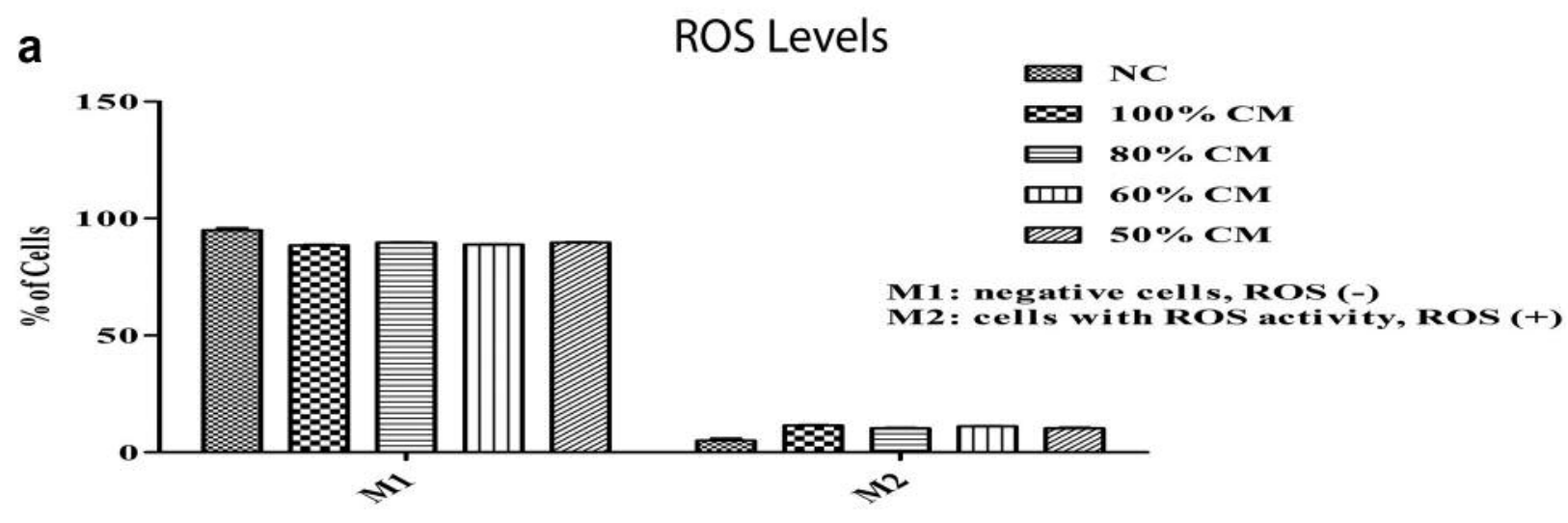

b

Cell cycle stages
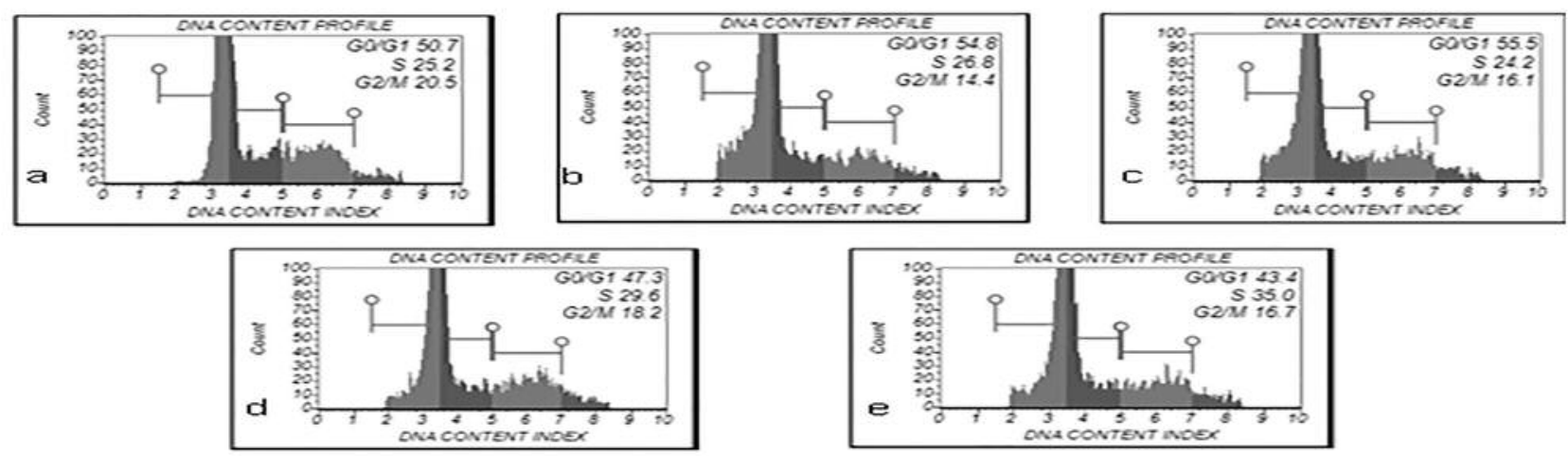

Figure 5. CCs conditioned media increased the levels of ROS a) ROS levels of BXPC-3 cells treated with various concentrations of CCs CM in b) Cell cycle phases of BXPC-3 cells treated with various concentrations of CCS CM, $p<0.0001$. 


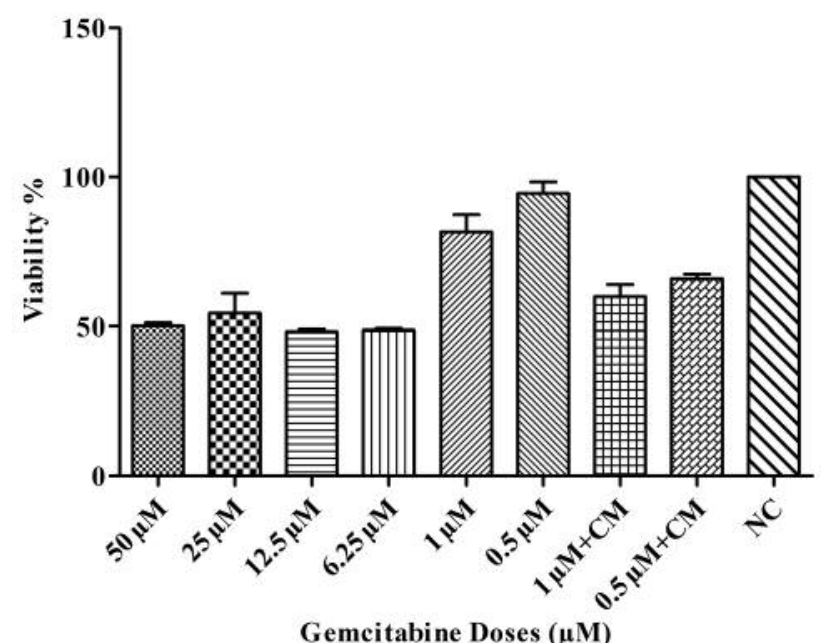

Figure 6. Combination of gemcitabine and CCs conditioned media reduced cell viability. Cell viability assay for combination therapy. NC: Negative control; $C M$ : conditioned medium, $p<0.0001$.

Reactive oxygen species (ROS) measurement. As shown in Figure 5a, there is an increase in the percentage of $\mathrm{BxPC}-3$ cells exhibiting increased levels of reactive oxygen species upon incubation with different concentrations of the CCs conditioned medium in relation to untreated cells.

Cell cycle analysis. Upon incubation of BxPC-3 cells with different concentration of $\mathrm{CCs}$ conditioned medium the percentage of cells in the $S$ phase increased and those in the $\mathrm{G}_{2} / \mathrm{M}$ phase decreased (Figure $5 \mathrm{~b}$ ).

Combination therapy. Treatment of $\mathrm{BxPC}-3$ cells with different doses of gemcitabine caused a reduction of cell viability (Figure 6). Higher levels of cell death were observed upon treatment of cells with the combination of CCs conditioned medium and $0.5 \mu \mathrm{M}$ or $1 \mu \mathrm{M}$ of gemcitabine compared to cells treated with $0.5 \mu \mathrm{M}$ or $1 \mu \mathrm{M}$ of gemcitabine alone (Figure 6).

Direct co-culture. As shown in Figure 7, after co-culture of GFP-tagged BxPC-3 cells with PKH26 Red fluorescent labelled Human CCs for $72 \mathrm{~h}$, the number of GFP-tagged BxPC-3 cells decreased, indicating that $\mathrm{BxPC}-3$ cells were undergoing apoptosis.

\section{Discussion}

The process of CCs expansion upon Luteinizing hormone (LH) stimulation requires the production of hyaluronic acid (HA) that accumulates in the extracellular space $(8,9)$. CCs express the surface receptor $\mathrm{CD} 44$, which binds to HA and allows the
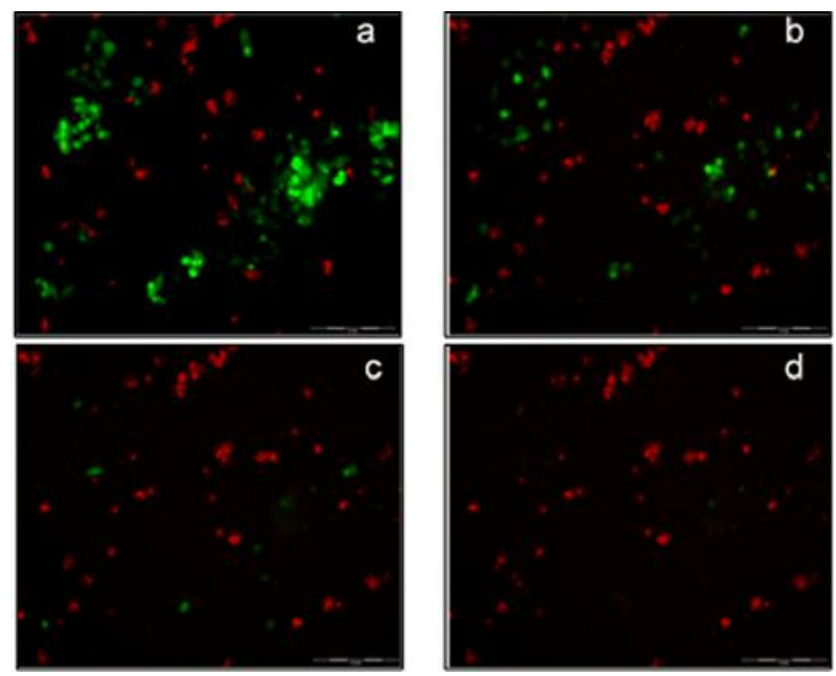

Figure 7. Direct co-culture of GFP tagged BxPC-3 cells with PKH26 Red fluorescent labelled Human Cumulus cells induced cell death. (a) $0 \mathrm{~h}$, (b) $24 \mathrm{~h}$, (c) $48 \mathrm{~h}$, (d) $72 \mathrm{~h}$.

formation of the extracellular matrix (ECM) between CCs (16). Overexpression of certain surface receptors have been used to distinguish malignant cells from benign ones (17). Among them, CD44 plays a critical role in metastasis (18) and is associated with bad prognosis (19). We examined the effect of conditioned medium of CCs on the growth and viability of pancreatic tumor cells. CCs conditioned medium of varying concentrations induced apoptosis, as assessed by various assays. Pancreatic cancer cells are very resistant to apoptosis (20), however, co-culturing with different concentrations of CCs conditioned medium $(100 \%, 80 \%, 60 \%$, and $50 \%)$ induced approximately $25 \%, 24 \%, 20 \%$, and $17 \%$ cell death, respectively. There was also a parallel increase in caspase activity, suggesting the detrimental effect of CCs conditioned medium over cancer cells. Downregulation of BCL2 and slight upregulation in caspase 3 (casp3) and Tp53 genes along with non-significant changes in Bax, Bak and TNF genes suggests that cell death is independent on BAX, and probably BAK, and might proceed through the intrinsic mitochondrial apoptosis pathway (21).

Our data are consistent with a published study showing the anti-proliferative and apoptotic effect of human umbilical cord mesenchymal stem cells (hUCMSCs) conditioned medium (22). An increase in the percentage of BxPC-3 cells exhibiting increased levels of ROS upon incubation with CCs conditioned medium was observed as suggested by others $(23,24)$. In addition, CCs conditioned medium influenced cell cycle and caused an arrest in the $\mathrm{S}$ phase, accumulation of cells in which DNA replication is blocked, and ultimately apoptosis (25). 
We further examined the synergistic effect of CCs conditioned medium and gemcitabine, the first line of conventional chemotherapy, for pancreatic ductal adenocarcinoma cells. As has been demonstrated in a similar study performed by Morisaki et al., the combination of CCs conditioned medium and a low dose of gemcitabine (as low as $1 \mu \mathrm{M}$ ) increases the percentage of growth inhibition (26). This synergistic effect enabled us to decrease the dose of gemcitabine, which will decrease the side-effects improving the quality of life of cancer patients.

\section{Conflicts of Interest}

The Authors declare that they have no conflicts of interest regarding this study.

\section{Authors' Contributions}

Concept, design (CAE, MEE), definition of intellectual content (CAE, MEE, YS), literature search (MEE, YS, CAE, FC, SF, NB), experimental studies (MEE, AAO), data acquisition (CAE, MEE), data analysis (MEE, CAE, YS, SF), manuscript preparation (MEE, CAE), manuscript editing (CAE, MEE, YS, SF), manuscript review (CAE, MEE, SF, NB).

\section{Acknowledgements}

The Authors thank Burcin Asutay for performing flow cytometry and live cell imaging analyses. This work was generously supported by Yeditepe University.

\section{References}

1 Gilchrist RB, Lane M and Thompson JG: Oocyte-secreted factors: Regulators of cumulus cell function and oocyte quality. Hum Reprod Update 14(2): 159-177, 2008. PMID: 18175787. DOI: 10.1093/humupd/dmm040

2 Tanghe S, Van Soom A, Nauwynck H, Coryn M and De Kruif A: Minireview: Functions of the cumulus oophorus during oocyte maturation, ovulation, and fertilization. Mol Reprod Dev 61(3): 414-424, 2002. PMID: 11835587. DOI: $10.1002 / \mathrm{mrd} .10102$

3 Dekel N and Beers WH: Development of the rat oocyte invitro - inhibition and induction of maturation in the presence or absence of the cumulus oophorus. Dev Biol 75(2): 247-254, 1980. PMID: 6154623. DOI: 10.1016/0012-1606(80)90160-8

4 Larsen WJ, Wert SE and Brunner GD: A dramatic loss of cumulus cell gap-junctions is correlated with germinal vesicle breakdown in rat oocytes. Dev Biol 113(2): 517-521, 1986. PMID: 3949077. DOI: 10.1016/0012-1606(86)90187-9

5 Ortiz ME, Lucero P and Croxatto HB: Post-ovulatory aging of human ova .2. Spontaneous division of the 1st polar body. Gamete Res 7(3): 269-276, 1983. DOI: 10.1002/mrd.1120070308

6 Diaz FJ, Wigglesworth K and Eppig JJ: Oocytes determine cumulus cell lineage in mouse ovarian follicles. J Cell Sci 120(8): 1330-1340, 2007. PMID: 17389684. DOI: 10.1242/jcs.000968

7 Liou GY and Storz P: Reactive oxygen species in cancer. Free Radic Res 44(5): 479-496, 2010. PMID: 20370557. DOI: $10.3109 / 10715761003667554$
8 Eppig JJ: Intercommunication between mammalian oocytes and companion somatic-cells. Bioessays 13(11): 569-574, 1991. PMID: 1772412. DOI: 10.1002/bies.950131105

9 Richards JS, Russell DL, Ochsner S and Espey LL: Ovulation: New dimensions and new regulators of the inflammatory-like response. Annu Rev Physiol 64: 69-92, 2002. PMID: 11826264. DOI: 10.1146/annurev.physiol.64.081501.131029

10 Mattheolabakis G, Milane L, Singh A and Amiji MM: Hyaluronic acid targeting of cd44 for cancer therapy: From receptor biology to nanomedicine. J Drug Target 23(7-8): 605618, 2015. PMID: 26453158. DOI: 10.3109/1061 186X.2015.1052072

11 Chen C, Zhao SJ, Karnad A and Freeman JW: The biology and role of CD44 in cancer progression: Therapeutic implications. J Hematol Oncol 11(1): 64, 2018. PMID: 29747682. DOI: 10.1186/s 13045-018-0605-5

12 Ahmmed B, Khan MN, Nisar MA, Kampo S, Zheng Q, Li YL and Yan Q: Tunicamycin enhances the suppressive effects of cisplatin on lung cancer growth through PTX3 glycosylation via AKT/NFkB signaling pathway. Int J Oncol 54(2): 431-442, 2019. PMID: 30483742 . DOI: $10.3892 /$ ijo.2018.4650

13 Cai JL, Li M and Na YQ: Correlation between hyaluronic acid, hyaluronic acid synthase and human renal clear cell carcinoma. Chin J Cancer Res 23(1): 59-63, 2011. PMID: 23467480. DOI: 10.1007/s11670-011-0059-6

14 Mauritz I, Westermayer S, Marian B, Erlach N, Grusch M and Holzmann K: Prostaglandin e-2 stimulates progression-related gene expression in early colorectal adenoma cells. Br J Cancer 94(11): 1718-1725, 2006. PMID: 16685273. DOI: 10.1038/ sj.bjc. 6603146

15 Paznekas WA, Boyadjiev SA, Shapiro RE, Daniels O, Wollnik B, Keegan CE, Innis JW, Dinulos MB, Christian C, Hannibal MC and Jabs EW: Connexin 43 (gja1) mutations cause the pleiotropic phenotype of oculodentodigital dysplasia. Am J Hum Genet 72(2): 408-418, 2003. PMID: 12457340. DOI: 10.1086/ 346090

16 Hernandez D L-BB, López-Bayghen E: Cultivating a support network: Granulosa cells and the needed knowledge on their role in oocyte maturation. Glob J Reprod Med 1(2), 2017. DOI: 10.19080/GJORM.2017.01.555556

17 Mattheolabakis G, Rigas B and Constantinides PP: Nanodelivery strategies in cancer chemotherapy: Biological rationale and pharmaceutical perspectives. Nanomedicine (Lond) 7(10): 15771590, 2012. PMID: 23148540. DOI: $10.2217 / \mathrm{nnm} .12 .128$

18 Gvozdenovic A, Arlt MJE, Campanile C, Brennecke P, Husmann K, Li YF, Born W, Muff R and Fuchs B: CD44 enhances tumor formation and lung metastasis in experimental osteosarcoma and is an additional predictor for poor patient outcome. J Bone Miner Res 28(4): 838-847, 2013. PMID: 23169460. DOI: 10.1002/ jbmr.1817

19 Uyar A, Torrealday S and Seli E: Cumulus and granulosa cell markers of oocyte and embryo quality. Fertil Steril 99(4): 979997, 2013. PMID: 23498999. DOI: 10.1016/j.fertnstert. 2013.01.129

20 Grasso C, Jansen G and Giovannetti E: Drug resistance in pancreatic cancer: Impact of altered energy metabolism. Critical Rev Oncol Hematol 114: 139-152, 2017. PMID: 28477742. DOI: 10.1016/j.critrevonc. 2017.03 .026

21 Lomonosova E, Ryerse J and Chinnadurai G: Bax/bakindependent mitoptosis during cell death induced by proteasome 
inhibition? Mol Cancer Res 7(8): 1268-1284, 2009. PMID: 19671675. DOI: 10.1158/1541-7786.MCR-08-0183

22 Yuan Y, Zhou C, Chen X, Tao CL, Cheng HQ and Lu X: Suppression of tumor cell proliferation and migration by human umbilical cord mesenchymal stem cells: A possible role for apoptosis and wnt signaling. Oncol Lett 15(6): 8536-8544, 2018. PMID: 29805590. DOI: 10.3892/ol.2018.8368

23 Chen Y, Azad MB and Gibson SB: Superoxide is the major reactive oxygen species regulating autophagy. Cell Death Differ 16(7): 1040-1052, 2009. PMID: 19407826. DOI: 10.1038/ cdd.2009.49

24 Hancock JT, Desikan R and Neill SJ: Role of reactive oxygen species in cell signalling pathways. Biochem Soc Trans 29: 345350, 2001. PMID: 11356180. DOI: 10.1042/0300-5127:0290345
$25 \mathrm{Xu} \mathrm{XH}$, Hamhouyia F, Thomas SD, Burke TJ, Girvan AC, McGregor WG, Trent JO, Miller DM and Bates PJ: Inhibition of DNA replication and induction of $\mathrm{s}$ phase cell cycle arrest by grich oligonucleotides. J Biol Chem 276(46): 43221-43230, 2001. PMID: 11555643. DOI: $10.1074 /$ jbc.M104446200

26 Morisaki T, Hirano T, Koya N, Kiyota A, Tanaka H, Umebayashi M, Onishi $\mathrm{H}$ and Katano M: Nkg2d-directed cytokine-activated killer lymphocyte therapy combined with gemcitabine for patients with chemoresistant metastatic solid tumors. Anticancer Res 34(8): 4529-4538, 2014. PMID: 25075096.

Received July 23, 2019

Revised August 8, 2019 Accepted August 20, 2019 